\title{
SISTEM ANALISA DAN PENENTU KELAYAKAN KENDARAAN BERMOTOR PADA KANTOR DINAS PERHUBUNGAN KABUPATEN HULU SUNGAI UTARA
}

\author{
Johan Wahyudi \\ Program Studi Teknik Informatika, STMIK Indonesia Banjarmasin \\ Jalan Pangeran Hidayatullah Banua Anyar Banjarmasin, Kalimantan Selatan \\ Email : johan77@stmik.id
}

\begin{abstract}
Abstrak - Data untuk menganalisa dan menentukan kelayakan sebuah kendaraan bermotor saat ini masih mengandalkan kemampuan visual dari petugas yang memeriksa kelayakan kendaraan bermotor. Dalam hal ini bisa terjadi kesalahan kecil yang kadang tidak terdeteksi dalam menentukan kelayakan kendaraan bermotor. Agar mengurangi kesalahan tersebut, diperlukan sistem komputer yang dapat mengolah data yang diinputkan dari hasil pemeriksaan untuk dapat menganalisa dan menentukan kelayakan dari kendaraan bermotor yang diperiksa. Sistem komputer yang dibangun disesuaikan dengan sistem pemeriksaan kelayakan kendaraan bermotor yang berjalan di Dinas Perhubungan Kabupaten Hulu Sungai Utara. Tujuan dari penelitian ini yaitu untuk mengetahui dan menganalisis kelayakan berkala kendaraan bermotor pada Unit Pelaksana Teknis Pengujian Kendaraan Bermotor Dinas Perhubungan Kabupaten Hulu Sungai Utara. Metode penelitian yang digunakan adalah metode penelitian deskriptif dengan data kuantitatif. Sampel yang diambil berjumlah 85 responden pelanggan uji kelayakan kendaraan dengan menggunakan accidental sampling. Penelitian ini dilakukan di Unit Pelaksana Teknis Pengujian Kendaraan Bermotor Kabupaten Hulu Sungai Utara. Pengumpulan data yang digunakan adalah wawancara, observasi, kuisioner, dokumentasi dan studi pustaka. Efektifitas pelayanan menjadi harapan pemerintah dan masyarakat pengguna jasa pengujian kendaraan bermotor agar tujuan dari pelaksanaan pelayanan tersebut dapat memberikan pelayanan pengujian kendaraan bermotor yang terbaik kepada masyarakat saat pengujian kendaraan bermotor serta penerimaan pemerintah dari pengujian kendaraan bermotor. Adapun data utama yang diinputkan adalah data user, data petugas, dan data registrasi. Kemudian dilakukan proses pendataan administrasi yang diinputkan melalui form input data pemeriksaan dan form input data penerbitan surat laik jalan. Adapun laporan yang dibuat adalah laporan data petugas, laporan data registrasi, laporan data hasil pemeriksaan dan laporan data kelayakan.
\end{abstract}

Kata Kunci : Pemeriksaan, Kelayakan Pengujian

\section{PENDAHULUAN}

$\mathrm{K}$ elayakan sebuah kendaraan bermotor agar laik jalan sangatlah diperlukan agar pada saat berada dijalan raya tidak membahayakan orang lain. Hal ini merupakan tugas dari Dinas Perhubungan Kabupaten Hulu Sungai Utara untuk memantau kelayakan dari kendaraan bermotor yang berada di wilayah Kabupaten Hulu Sungai Utara. Pemeriksaan kelayakan kendaraan bermotor dilakukan secara berkala agar dapat mengetahui kelayakan dari kendaraan bermotor tersebut sebelum diberikan ijin oleh Dinas Perhubungan.

Penanganan data untuk menganalisa dan menentukan kelayakan sebuah kendaraan bermotor saat ini masih mengandalkan kemampuan visual dari petugas pemeriksa. Dalam hal ini bisa terjadi kesalahan kecil yang kadang tidak terdeteksi dalam menentukan kelayakan kendaraan bermotor. Agar mengurangi kesalahan tersebut, diperlukan sistem komputer yang dapat mengolah data yang diinputkan dari hasil pemeriksaan untuk dapat menganalisa dan menentukan kelayakan dari kendaraan bermotor yang diperiksa. Sistem komputer yang dibangun disesuaikan dengan sistem pemeriksaan yang berjalan di Dinas Perhubungan Kabupaten Hulu Sungai Utara.

Dalam mengolah data pemeriksaan kelayakan kendaraan bermotor untuk dianalisa dan ditentukan kelayakan dari kendaraan yang diperiksa. Data yang diolah data petugas pemeriksa, data registrasi pemeriksaan, data pemeriksaan, data pembayaran retribusi pemeriksaan kelayakan kendaraan bermotor dan data penerbitan surat kelayakan kendaraan bermotor. Proses input data untuk menganalisa hasil pemeriksaan kelayakan kendaraan untuk menentukan layak atau tidak kendaraan bermotor yang terdiri dari input data petugas pemeriksa, input data registrasi pemeriksaan, input data pemeriksaan, dan input data penerbitan surat kelayakan dan ijin opersional kendaraan.

Pelayanan pengujian kendaraan bermotor merupakan permasalahan yang penting yang ada pada Dinas Perhubungan dalam menangani secara efektif dan seseuai dengan undangundang yang mengatur tentang pengujian berkala kendaraan, karena inti dari penyelenggaraan pemerintahan daerah ialah bagaimana memberikan pelayanan yang baik sehingga penerimaan pendapatan asli daerah berjalan lancar serta kepentingan masyarakat pengguna kendaraan bermotor dapat terpenuhi. Efektifitas pelayanan menjadi harapan pemerintah dan masyarakat pengguna jasa pengujian kendaraan bermotor agar tujuan dari pelaksanaan pelayanan tersebut dapat memberikan pelayanan pengujian kendaraan bermotor yang terbaik kepada masyarakat pengguna jasa pengujian kendaraan bermotor serta penerimaan pemerintah dari pengujian kendaraan bermotor tersebut bisa masuk dalam pajak penerimaan daerah dapat terwujud.

Analisis data yang dilakukan oleh penulis yakni distribusi frekuensi, penyajian grafik untuk mendeskripsikan distribusi frekuensi, perhitungan modus, dan perhitungan nilai rata-rata (mean). Hasil penelitian yang diperoleh, menurut pemohon uji kelayakan kendaraan bermotor tentang kinerja pelayanan uji kelayakan kendaraan bermotor memiliki nilai mean. Hasil tersebut termasuk kategori jawaban setuju yang berarti kinerja pelayanan uji kelayakan kendaraan bermotor di Dinas Perhubungan Kabupaten Hulu Sungai Utara kendaraan bermotor dapat dikatakan baik oleh masyarakat. 


\section{METODE PENELITIAN}

\section{A. Pengujian Kendaraan Sesuai UU}

Efektifitas dari Undang-Undang No 22 Tahun 2012 tentang lalu lintas dan angkutan jalan, sesuai perspektif dari efektifitas pengujian kendaraan, Dalam menangani kefektifan dan layaknya suatu kendaraan dalam pengujian kendaraan tentunya banyak sekali permasalahan yang dihadapi, mulai dari sistem pengujian berkalanya yang kurang memadai untuk pengujian kendaraan sehingga kendaraan tersebut meski mengikuti pengujian berkala tetapi dalam proses pelaksanaannya masih belum memadai.
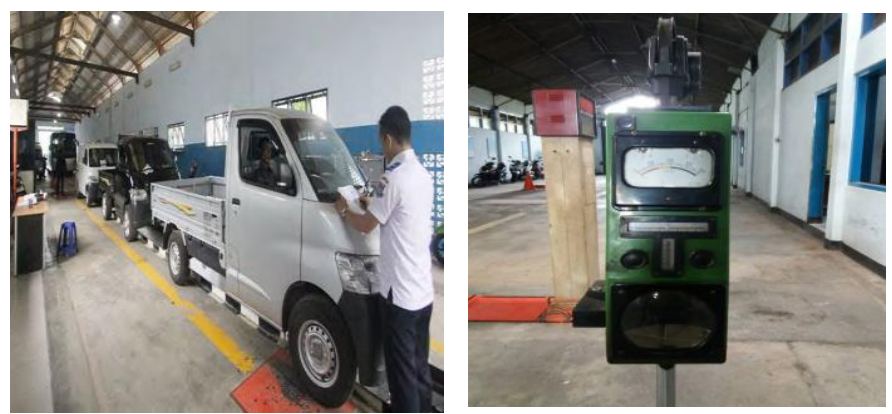

Gambar 1. Alat Uji Pif Lift dan Axle Play Detector

Didalam Peraturan Pemerintah Nomor 55 tahun 2012 Tentang uji kendaraan disebutkan bahwa syarat layak suatu kendaraan harus disertai dengan kelayakan kendaraan tersebut. Tentang efektif kelayakan atau tidaknya kendaraan bermotor dapat diketahui ketika kendaraan tersebut melakukan pengujian kelayakan kendaraan, kendaraan akan diuji oleh petugas uji secara detail dan ketat untuk bisa dikatakan layak jalan. Didalam pengujian kendaraan ini kendaraan khususnya pengangkut barang akan diujikan dengan melalui beberapa tahap sehingga keefektifan dalam pengujian kendaraan benarbenar efektif dan sesuai perspektif undang-undang.
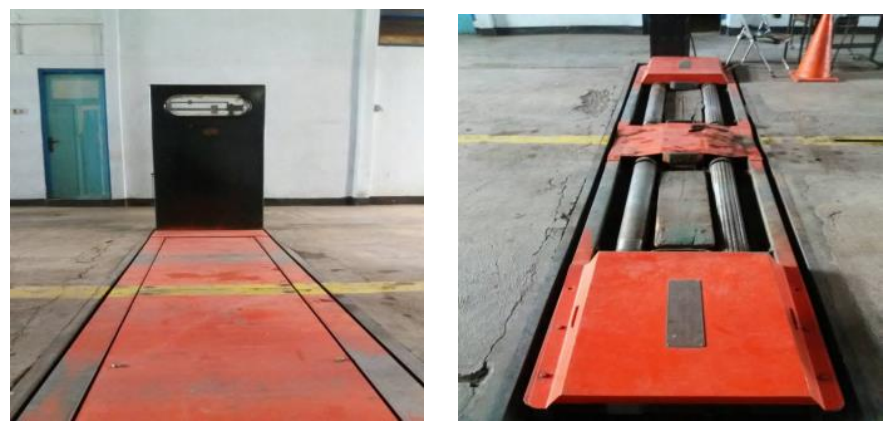

Gambar 2. Alat Uji Side Slide Tester dan Brake Tester

\section{B. Metode Pengumpulan Data}

Prosees pengambilan data yang terarah dan tepat maka penelitian akan terlaksana dengan sistematis sehingga data yang di dapatkan merupakan data yang akurat dan dapat diolah serta bermanfaat, adapun teknik pengumpulan data yang digunakan yaitu, antara lain :

a. Observasi, yaitu dengan cara melakukan pengamatan pada Dinas Perhubungan, Kabupaten Hulu Sungai Utara terhadap hal-hal yang dianggap perlu dan berkaitan dengan materi yang dibahas.

b. Dokumentasi, yaitu dengan cara mengumpulkan data-data yang diperlukan dalam penelitian pada Dinas Perhubungan Kabupaten Hulu Sungai Utara.

c. Wawancara, yaitu melakukan wawancara dengan orang atau pihak yang ada di kantor atau yang berkaitan dengan sistem yang akan dibuat.

d. Studi Pustaka, yaitu mempelajari buku, artikel dan situs pendukung untuk melandasi teori pada metode yang dipakai pada penelitian ini.

\section{Rancangan Model Sistem}

1. Diagram Konteks

Suatu diagram konteks selalu mengandung satu dan hanya satu proses saja. Proses ini mewakili proses dari seluruh sistem diagram konteks yang menggambarkan hubungan input atau output antara sistem dengan dunia luarnya (kesatuan luar). Adapun hasil perancangan diagram konteks aplikasi sistem analisa dan penentu kelayakan kendaraan bermotor pada Dinas Perhubungan Kabupaten Hulu Sungai Utara ini adalah,sebagai berikut :

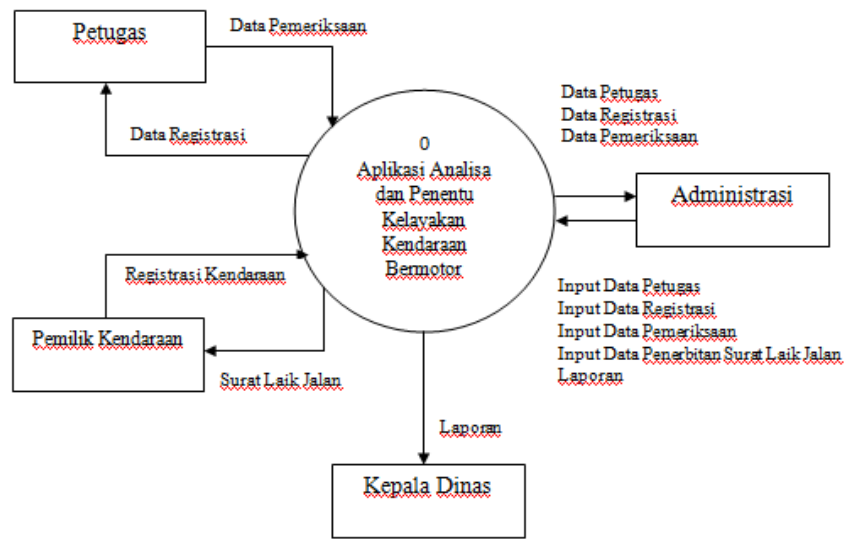

Gambar 3. Diagram Konteks

\section{Data Flow Diagram}

Data flow diagram yang digunakan pada penelitian ini adalah data flow diagram level 0 . Adapun data flow diagram dalam aplikasi ini pada Dinas Perhubungan Kabupaten Hulu Sungai Utara adalah: 


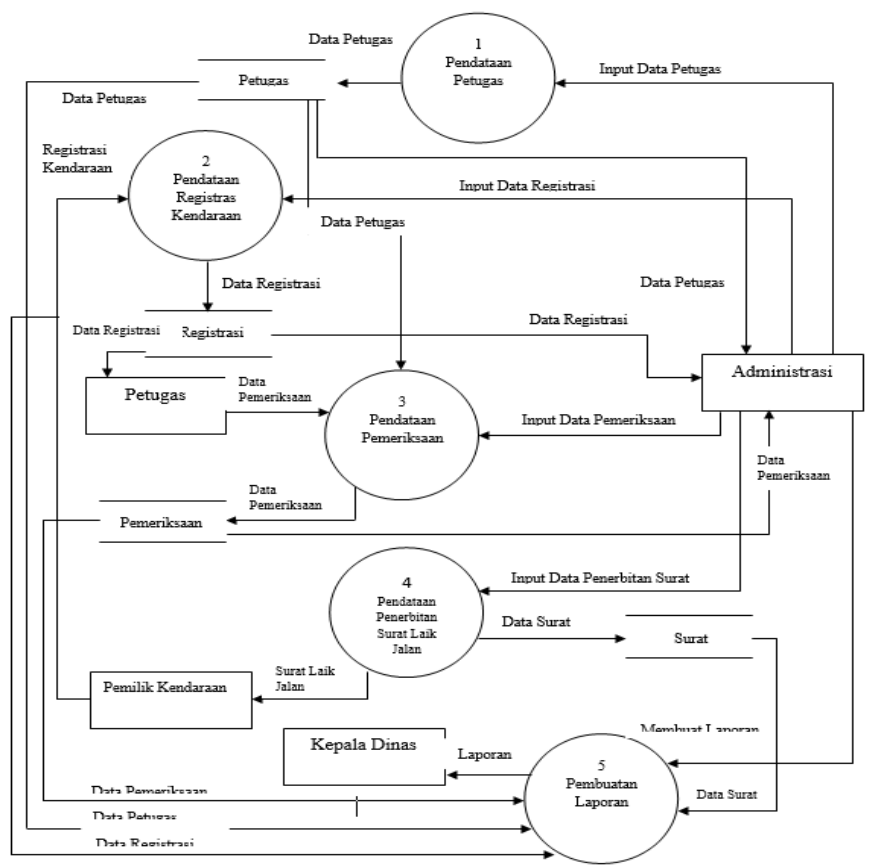

Gambar 4. Data Flow Diagram

\section{Relasi Antar Tabel}

Relasi antar tabel adalah hubungan yang terjadi pada suatu tabel dengan tabel yang lainnya, yang berfungsi untuk mengatur operasi suatu database. Adapun relasi antar tabel dalam aplikasi ini pada Dinas Perhubungan Kabupaten Hulu Sungai Utara adalah:

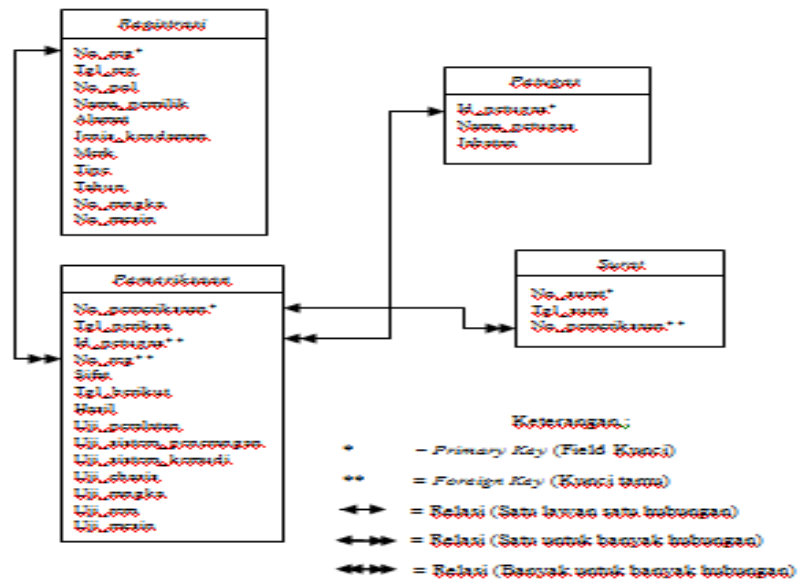

Gambar 5. Relasi Antar Tabel

\section{HASIL DAN PEMBAHASAN}

\section{A.Langkah Pembuatan Sistem}

Proses pembuatan aplikasi kelayakan kendaraan bermotor pada Dinas Perhubungan Kabupaten Hulu Sungai Utara ini menggunakan model waterfall. Model ini melakukan pendekatan secara sistematis dan urut, mulai dari analisis kebutuhan sistem, perancangan sistem, koding, pengujian dan maintenance. Adapun langkah-langkahnya adalah sebagai berikut:
1. Analisis persyaratan dan kebutuhan

Pada tahapan ini dilakukan pengumpulan data dan informasi yang berkaitan dengan pendataan syarat kelayakan kendaraan bermotor. Informasi ini diperoleh melalui dengan cara secara langsung datang ke lapangan dan mewawancarai beberapa orang narasumber. Data dan informasi yang telah didapatkan selanjutnya akan dianalisis untuk mendapatkan dokumentasi kebutuhan pengguna dan digunakan pada tahapan selanjutnya.

\section{Desain sistem}

Tahapan selanjutnya adalah membuat rancangan untuk aplikasi kelayakan kendaraan bermotor bagi Dinas Perhubungan Kabupaten Hulu Sungai Utara. Rancangan yang dibuat ini meliputi rancangan model sistem, rancangan antarmuka masukan sistem hingga rancangan antarmuka keluaran sistem.

3. Implementasi

Tahapan selanjutnya adalah mulai membangun sistem. Aplikasi kelayakan kendaraan bermotor ini menggunakan aplikasi Visual Studio 2010.

\section{Testing}

Pada tahapan ini aplikasi yang sudah selesai diprogram akan dilakukan proses pengujian. Pengujian ini dilakukan untuk memeriksa apakah fungsi aplikasi yang dibangun sudah sesuai dengan tujuan dan keinginan.

\section{Maintenance}

Setelah lolos tahap pengujian, tahapan selanjutnya adalah menerapkan aplikasi kelayakan kendaraan bermotor ini pada instansi Dinas Perhubungan Kabupaten Hulu Sungai Utara.

\section{B. Tampilan Aplikasi}

1. Menu Utama

Menu utama adalah tampilan yang muncul setelah admin berhasil login. Adapun menu utama dalam aplikasi ini adalah sebagai berikut :

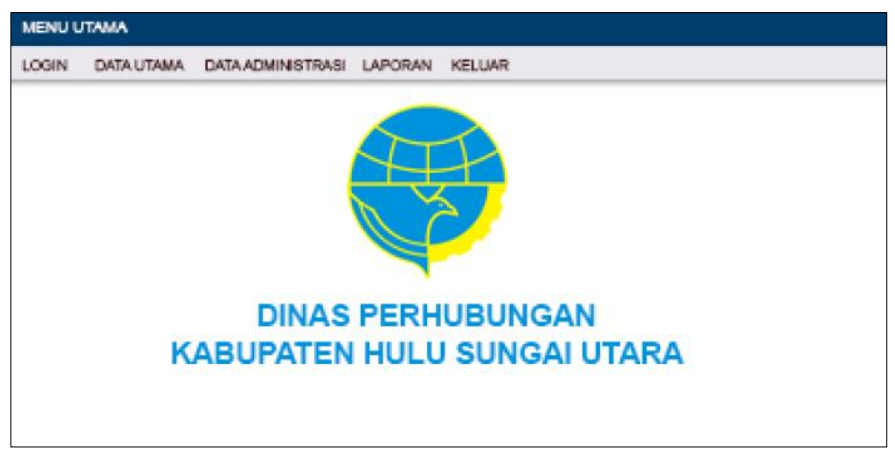

Gambar 6. Tampilan Menu Utama

2. Form Input Data Pengguna

Form ini berguna untuk menginputkan data pengguna yang terdiri dari username, password, dan status pengguna. Pada form terdapat fungsi tombol diantaranya tombol batal, simpan edit, hapus dan keluar. 


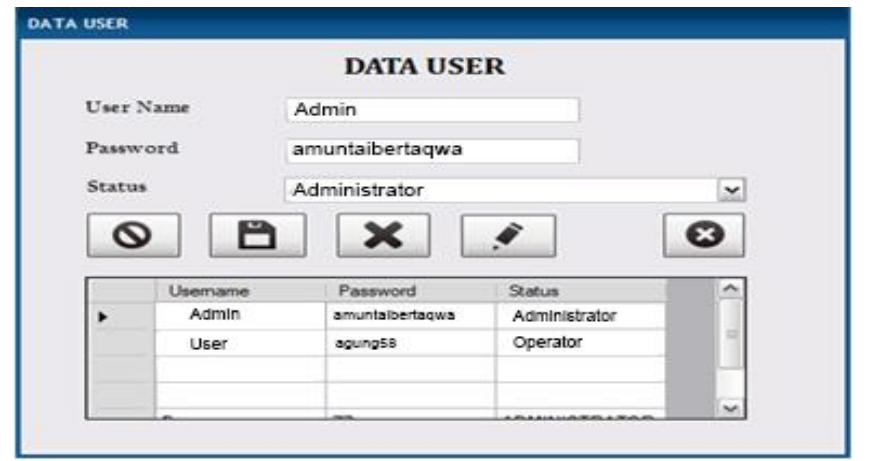

Gambar 7. Tampilan Data Pengguna

\section{Form Input Data Petugas}

Form ini berguna untuk menginputkan data petugas yang memeriksa kendaraan yang terdiri dari nomor id petugas, nama petugas, dan jabatan. Pada form terdapat fungsi tombol diantaranya adalah tombol batal, simpan, edit, hapus dan keluar.

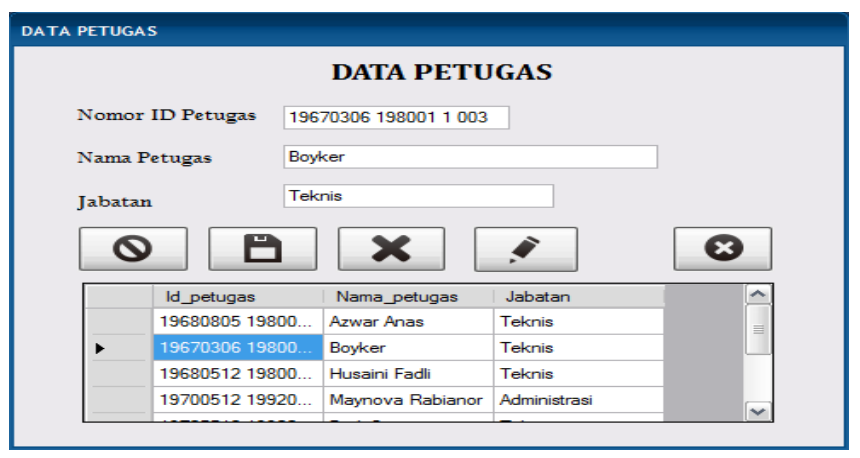

Gambar 8. Tampilan Data Pengguna

4. Form Input Data Registrasi

Form ini berguna untuk menginputkan data registrasi kendaraan bermotor yang akan diperiksa yang terdiri dari nomor registrasi, tanggal registrasi, nomor polisi, nama pemilik, alamat, jenis kendaraan, , merk, tahun, nomor rangka dan nomor mesin. Pada form terdapat fungsi tombol diantaranya adalah tombol batal, simpan, edit, hapus dan keluar.

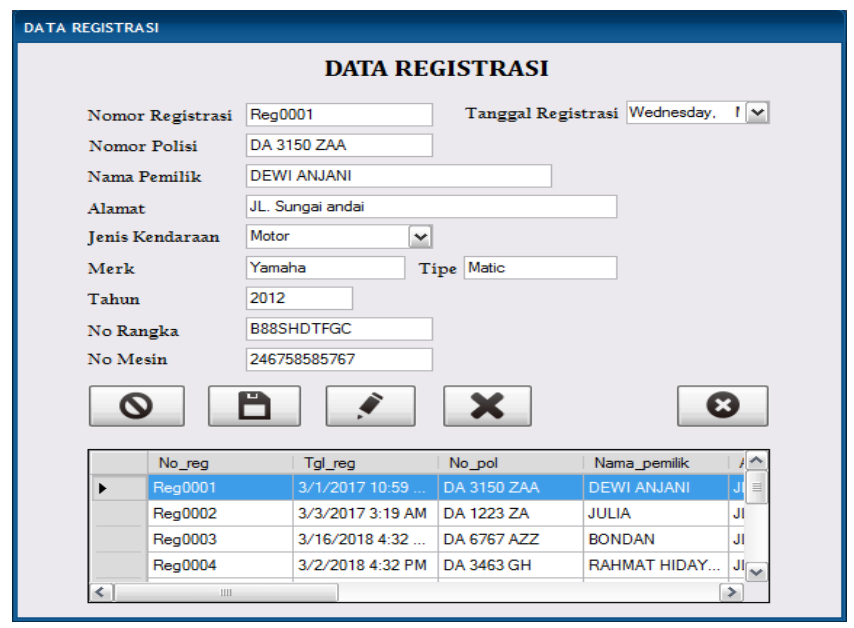

Gambar 9. Tampilan Data Registrasi
5. Form Input Data Pemeriksaan

Form ini berguna untuk menginputkan data pemeriksaan yang dilakukan dan mencentang hasil dari pemeriksaan dimana inputan pada form ini terdiri dari nomor pemeriksaan, tanggal periksa, nama petugas pemeriksa, nomor registrasi, sifat pemeriksaan, tanggal berikut, hasil pemeriksaan untuk setiap komponen uji dan hasil dari pemeriksaan keseluruhan komponen. Pada form terdapat fungsi tombol diantaranya adalah tombol batal, simpan, edit, hapus dan keluar.

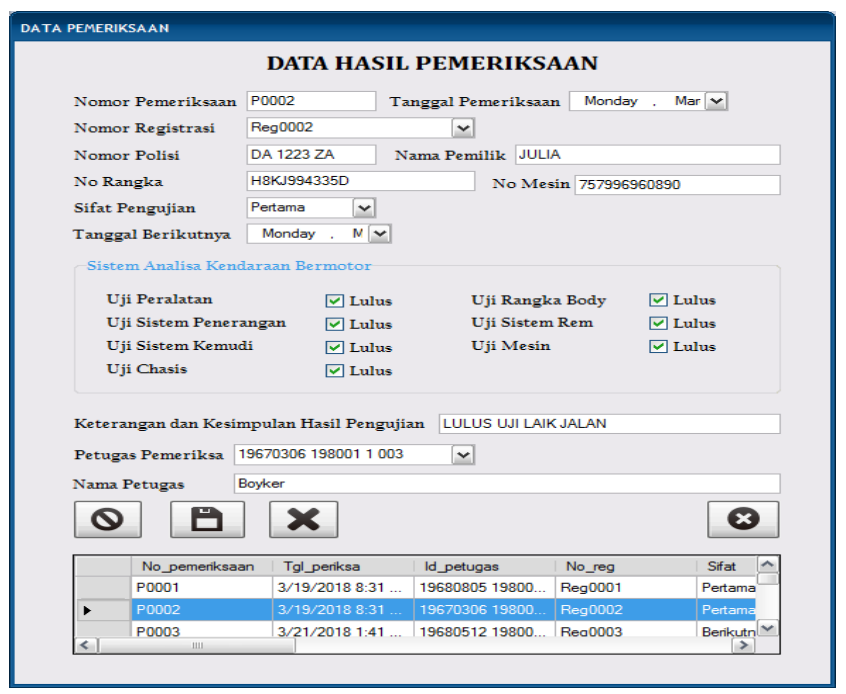

Gambar 10. Tampilan Data Pemeriksaan

6. Penerbitan Surat Hasil Pemeriksaan

Laporan ini akan menampilkan surat hasil pemeriksaan yang diinputkan dan disimpan di database yang ditampilkan melalui menu form. Berikut tampilan form dan bentuk laporan yang telah diinputkan data

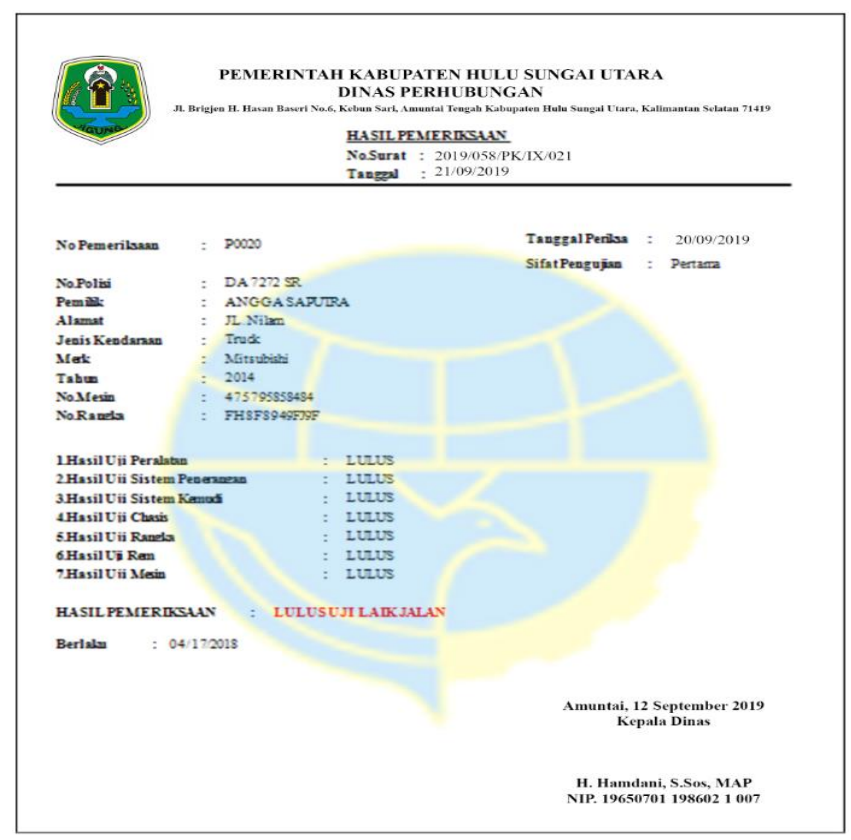

Gambar 11. Laporan Hasil Pemeriksaan 
7. Laporan Data Registrasi Pertahun

Laporan ini akan menampilkan data registrasi selama periode pertahun yang diinputkan dan disimpan di database yang ditampilkan melalui menu form. Berikut tampilan form dan bentuk laporan yang telah diinputkan data.

\begin{tabular}{|c|c|c|c|c|c|}
\hline (1) & $\begin{array}{r}\text { PEMERI } \\
\text { J. Brigjen H. Hasan Base } \\
\text { LA }\end{array}$ & $\begin{array}{r}\text { TAH KABUP } \\
\text { DINAS P } \\
\text { No.6, Kelua Sart, } \\
\text { ORAN DATA } \\
\end{array}$ & $\begin{array}{l}\text { TEN HUI } \\
\text { RHUBUN } \\
\text { atal Tengah Kal } \\
\text { Markiksu }\end{array}$ & $\begin{array}{l}\text { SUNGAI UT } \\
\text { AN } \\
\text { aten Hulu Sungat Ctar } \\
\text { nzx zurs }\end{array}$ & $\begin{array}{l}\text { RA } \\
\text { Kallimantan Selatan } 71419\end{array}$ \\
\hline Nopemenikasan & Samaremalk & Nobolin & sifst & Taveral Berilas & Bast \\
\hline D0001 & DEWIANONG & DA $3150 \mathrm{ZM}$ & Derrama & $03 / 192018$ & LULUSURLAR INAN \\
\hline$\$ 0002$ & TULLAMCARRA & $\mathrm{DA} 1223 \mathrm{ZA}$ & Dertana & $03 / 192018$ & LULUSURLAR INAN \\
\hline 20003 & BONDN & DAS707 AZZ & Pertana & $03 / 192018$ & LULUSUתLAR JNAN \\
\hline 70004 & RAKМСTKDAY & DA 2463 OH & Pertama & $03 / 192018$ & LUzUSUתLAxINAN \\
\hline pooss & Otrawes & DA997 หน & Dertama & $04 / 172015$ & TDAXLULUSURLAX \\
\hline 20000 & ANTO & DA:212 DO & Derrama & 04172018 & 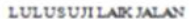 \\
\hline 00007 & A $\pi \Omega$ & $\mathrm{DA} 4363 \mathrm{MaS}$ & Dertama & $04 / 17 / 2018$ & TIDAKLULUSURLUK \\
\hline p000s & SUPRAANSYNH & DA5768 LT & Berikumy & $04 / 27 / 2018$ & LUZUSURLAR JNAN \\
\hline 70000 & KUSADIFADU & DA9454 DO & Berikvans & $04 / 172018$ & LURUSUILAR JNAN \\
\hline 70010 & ZAENAL ARPS: & $\mathrm{DA} 226 \mathrm{ER}$ & Dertama & $04 / 172013$ & TDAKLUZUS URLAX \\
\hline Doon & ZAKABU & DA5053 EU & Derrama & $04 / 172018$ & LULUSUHLAK JLAN \\
\hline$\$ 0012$ & HANDAN & DA $3433 \mathrm{ZZ}$ & Berikums & $04 / 172018$ & LULUSUILAR JNAN \\
\hline 20013 & FATMAH & DA $20 \mathrm{KY}$ & Derrama & $04 / 172018$ & TDAKLULUSURLAK \\
\hline \multicolumn{6}{|c|}{$\begin{array}{c}\text { Amuntai, } 12 \text { September } 2019 \\
\text { Kepala Dinas }\end{array}$} \\
\hline \multicolumn{6}{|c|}{$\begin{array}{l}\text { H. Hamdani, S.Sos, MAP } \\
\text { NIP. } 196507011986021007\end{array}$} \\
\hline
\end{tabular}

Gambar 10. Laporan Data Pemeriksaan Per Tahun

\section{Analisis Hasil Penelitian}

Dari aplikasi sistem penentuan kelayakan kendaraan bermotor yang telah dijelaskan diatas, didapatkan hasil penelitian seperti pada tabel dibawah ini :

Tabel 1. Hasil Pengujian Aplikasi

\begin{tabular}{|c|c|c|c|}
\hline No & Uji Aplikasi & Respon Aplikasi & Keterangan \\
\hline 1 & $\begin{array}{lr}\text { Menyimpan } & \text { data } \\
\text { pemeriksaan } & \text { sesuai } \\
\text { dengan } & \text { keinginan } \\
\text { pengguna } & \end{array}$ & $\begin{array}{l}\text { Dapat menyimpan } \\
\text { dan menampilkan } \\
\text { data pemeriksaan }\end{array}$ & Berhasil \\
\hline 2 & $\begin{array}{l}\text { Menyimpan dan } \\
\text { menampilkan data } \\
\text { registrasi kendaraan }\end{array}$ & $\begin{array}{l}\text { Dapat menyimpan } \\
\text { dan menampilkan } \\
\text { data registrasi }\end{array}$ & Berhasil \\
\hline 3 & $\begin{array}{lr}\text { Mencetak } & \text { surat } \\
\text { kelayakan } & \text { kendaraan } \\
\text { bermotor } & \end{array}$ & $\begin{array}{l}\text { Dapat mencetak } \\
\text { dan menampilkan } \\
\text { data registrasi dan } \\
\text { data pemeriksaan }\end{array}$ & Berhasil \\
\hline 4 & $\begin{array}{l}\text { Menampilkan data } \\
\text { kendaraan yang layak } \\
\text { jalan dan tidak layak } \\
\text { jalan }\end{array}$ & \begin{tabular}{lr}
\multicolumn{2}{l}{ Dapat memberikan } \\
informasi & tentang \\
kendaraan & yang \\
layak dan & tidak \\
layak &
\end{tabular} & Berhasil \\
\hline
\end{tabular}

\section{KESIMPULAN}

Dari hasil pembahasan yang telah dijelaskan pada bab sebelumnya mengenai aplikasi penentu kelayakan kendaraan bermotor yang diperiksa di Dinas Perhubungan Kabupaten
Hulu Sungai Utara dapat diambil kesimpulan sebagai berikut :

1. Perangkat lunak ini dapat mendata data user, data petugas dan data registrasi.

2. Kemudian dilakukan proses pendataan administrasi yang diinputkan melalui form input data pemeriksaan dan form input data penerbitan surat laik jalan.

3. Perangkat lunak ini dapat menghasilkan. Adapun laporan yang dibuat adalah laporan data petugas, laporan data registrasi, laporan data hasil pemeriksaan, dan laporan data rincian hasil pemeriksaan.

4. Perangkat lunak ini masih dalam tahap pengembangan dan perbaikan yang lebih baik lagi karena keterbatasan kemampuan dalam mengolah aplikasi yang kompleks.

5. Sistem yang digunakan dalam aplikasi ini sebatas penelitian yang dilakukan di kantor Dinas tersebut.

\section{SARAN}

Adapun saran untuk penelitian selanjutnya yaitu sebagai berikut:

1. Kedepannya sistem penentuan kelayakan kendaraan ini bisa dikembangkan untuk bisa secara online.

2. Aplikasi ini dapat dikembangkan lebih baik lagi agar dapat menunjang administrasi pada menentukan kelayakan kendaraan bermotor yang diperiksa di Dinas Perhubungan Kabupaten Hulu Sungai Utara.

\section{DAFTAR PUSTAKA}

[1] A.Bishop Gary, Donald H.Stedman dan Lowell Ashbaugh, 2012. Motor Vehicle Emissions Variability

[2] Assauri, Sofjan, 2008. Pengertian Periodic Maintenance, Penerbit Sinar Baru, Bandung.

[3] Ichwan, Muhammad. 2011. Pemrograman Basis Data : Microsoft Visual Basic 6.0 dan MySql. Bandung : Informatika

[4] Jogiyanto, H.M, 2005. Pengertian Rancang Bangun. Penerbit Andi Offset, Yogyakarta.

[5] Jogiyanto, H.M, 1993. Analisa dan Desain Informatika, Andi Offset, Yogyakarta.

[6] Kendall, 2003, Analisis dan Perancangan sistem Sistem Jilid 1. Jakarta: PT. Prehallindo

[7] Khaidir. (2004). Microsoft Visual Basic 6.0. Jakarta: Elex Media Komputindo.

[8] Nurdjanah, Nunuj, 2012. Analisis Implementasi Pengujian Berkala Kendaraan Bermotor Pada Studi Kasus : Implementasi Pengujian Berkala di Kota Bandung.

[9] Samsinar, 2014. Desain Sistem Informasi Pengujian Kendaraan Bermotor Pada UPT. PKB Kendaraan Khusus Cilincing, Bandung.

[10] Saputro, Rela Eka Andik, 2013. Sistem Informasi Manajemen Pengujian Kendaraan Bermotor Kabupaten Magetan Menggunakan Visual Basic 6.0

[11]Sutanta, E, 1996. Sistem Basis Data : Konsep Dan Perancangan Dalam Sistem Informasi Manajemen. Edisi I. Andi Offset. Yogyakarta

[12] Supriyanto. 2005. Perancangan Aplikasi. Surabaya: Widyastana. 